www.jmscr.igmpublication.org

Index Copernicus Value: 79.54

ISSN (e)-2347-176x ISSN (p) 2455-0450

crossref DOI: https://dx.doi.org/10.18535/jmscr/v7i4.118

Journal Of Medical Science And Clinical Research

IGM Publication

An Official Publication of IGM Publication

Original Research Article

\title{
Clinicoepidemiological and mycological study of tinea capitis: A study from a tertiary care centre
}

\author{
Authors

\section{Dr Anjani Kumar Shukla ${ }^{1}$, Dr Bibhuti Bhushan ${ }^{*}$, Dr Dharmendra Kumar Mishra ${ }^{3}$,} \\ Dr Shyam Sundar Chaudhary ${ }^{4}$, Dr Ichchhit Bharat ${ }^{5}$, Dr Sukanta Sen ${ }^{6}$
}

${ }^{1}$ Assistant Professor, Department of Dermatology, Shri Ramkrishna Institute of Medical Sciences, Kanksha, Durgapur, Malandighi, West Bengal 713212

${ }^{2}$ Assistant Professor, Department of General Medicine, Gouri Devi Institute of Medical Sciences \&

Hospital, G.T. Road, Rajbandh, Durgapur, West Bengal 713212

${ }^{3,4}$ Professor, Department of Dermatology, Venereology and Leprosy, Rajendra Institute of Medical Sciences, Bariatu, Ranchi, Jharkhand 834009

${ }^{5}$ Senior Resident, Department of Dermatology, Mata Gujri Memorial Medical College \& LSK Hospital ,

Purabbali, Dinajpur Road, Kishanganj, Bihar 855108

${ }^{6}$ Professor, Department of Pharmacology, ICARE Institute of Medical Sciences \& Research, Banbishnupur, Haldia, West Bengal 721645

*Corresponding Author

Dr Bibhuti Bhushan

Email: dr.bbhushan1982@gmail.com, Contact No.: 9932071111

\begin{abstract}
Background: Dermatophytoses are the most common of the superficial fungal infections. Tinea capitis is a superficial fungal infection that predominantly affects the pediatric population. It is common in tropics and may present in epidemic proportions in areas with high rates of humidity. The clinicoepidemiological and mycological aspects of this tinea capitis infection were studied in a tertiary care centre in Ranchi, Jharkhand.

Materials \& Methods: One hundred sixty patients with positive KOH microscopy were underwent detailed history regarding age, sex, duration and progression of disease socioeconomic status and clinical symptoms and findings were recorded in specifically predesigned proforma. In addition to this a history of similar disease in past, in the family, history of comb sharing, oil application and association with pets was also evaluated.

Results: Most common symptom in the present study was scaling, reported in $94.9 \%$ of the patients followed by itching, hair loss, and papules in $78.4 \%, 69.6 \%$, and $31.6 \%$ of the patients respectively. Among the patients with localized scalp involvement, vertex was the most common site involved in $40(25 \%)$ of the patients followed by parietal, occipital, temporal and frontal in 26 (16\%), 18(11\%), 06(3.7\%) and $06(3.7 \%)$ patients respectively.

Conclusion: Grey patch is the most common variant of $T$ capitis. T. violaceum is the most common isolate in all the clinical variants of $T$ capitis in North eastern part of India. Anthropophilic species are responsible mainly for non inflammatory variants and zoophilic species for inflammatory variants. Intra-familial and animal contacts are major source of the source of infection.

Keywords: Tinea capitis, Dermatophytosis, Clinical features, Mycological study.
\end{abstract}




\section{Introduction}

Tinea capitis is a dermatophyte infection that involves the scalp, hair follicles, and the adjoining skin. Dermatophytes are fungi that commonly infect the keratinous tissues of humans and some lower animals. The superficial layers of the epidermis, particularly the stratum corneum, and the keratin rich appendages, such as the hair and nails of the living host, are invaded by these dermatophytes, where they eventually proliferate and multiply. ${ }^{1}$ It is a common scalp infection seen in children from developing countries, often causing varying degrees of hair loss. ${ }^{2,3} \mathrm{~T}$ capitis has a variety of clinical presentations ranging from asymptomatic carrier state, noninflammatory varieties like grey patch alopecia, to inflammatory varieties like kerion and favus. Noninflammatory forms are more common than the inflammatory forms. In India, grey patch is the most common variant and has been reported in up to $60 \%$ of the cases. ${ }^{4}$ There is an immense need to control and treat this infection not only to prevent its complication of scarring alopecia but also to avoid social ostracism faced by patients of $T$. Capitis in their school and play environment due to itchy scalp and hair loss. ${ }^{5,6} \mathrm{~T}$ capitis is caused by a variety of dermatophytes in the genera Microsporum and Trichopyton. Studies on epidemiology of $\mathrm{T}$. capitis suggest that the pattern of causative agents in western countries has been changing with decrease incidence of Microsporum canis and increase in Trichophyton tonsurans ( $T$ tonsurans) infection. ${ }^{7} \mathrm{~T}$. violeceum has been the predominant pathogen of $\mathrm{T}$. capitis in Indian subcontinent and in parts of Far East. ${ }^{8}$

We attempt to assess its various clinical manifestations, the most common sites and clinical patterns, causative agents and predisposing factors of the $\mathrm{T}$ capitis. The efficacy of laboratory methods in confirming clinical diagnosis and species identification has also been assessed, carried out at a tertiary care hospital in Ranchi, Jharkhand.

\section{Materials \& Methods}

One hundred fifty eight, untreated cases of tinea capitis, irrespective of sex and socioeconomic status, of age group 2 to 12 years of age, attending Department of Dermatology, Venerology and Leprology of RIMS, from September 2011 to august 2012, who fulfilled inclusion criteria were included. The study was taken approval by the ethical committee of institution of RIMS.

A clinical diagnosis of T.capitis was made in patients with scaly scalp lesions with or without alopecia, patients with inflammatory boggy mass studded with scales and crust, and patient with diffuse scaling on scalp, not responding to usual treatment. An informed consent was taken from the patient/or/guardian and then scraping material/hair from the lesions of scalp of patient subjected to $\mathrm{KOH}$ microscopic examination. The patient showing positive microscopic finding for dermaotophytes in the $\mathrm{KOH}$ preparation were subjected to detailed history through clinical examination and investigation as per the predesigned proforma.

\section{Clinical history}

One hundred sixty patients with positive $\mathrm{KOH}$ microscopy were underwent detailed history regarding age, sex, duration and progression of disease socioeconomic status and clinical symptoms and findings were recorded in specifically predesigned proforma. In addition to this a history of similar disease in past, in the family, history of comb sharing, oil application and association with pets was also evaluated.

\section{Classification}

All patients were then classified according to clinical presentations into-

Non-inflammatory variants: Grey patch and Black dot.

Inflammatory variant: kerion and favus

\section{KOH Microscopy}

The lesions were decontaminated with $70 \%$ alcohol. Small scales were scraped off from the margins by rounded scalpel or glass slide. Affected hair was collected by removing them completely using an epilation forceps. Scales were 
then put on a clean glass slide. Scales and hair debris were mixed with $10 \% \mathrm{KOH}$. A coverslip was applied and the slide heated gently over a flame. It was then examined under the microscope in 10x and 40x magnification.

\section{Fungal -culture}

Hair were plucked from the affected area with a sterile forceps along with scraping of the scales and inoculated in the medium for culture. Sabouraud's Dextrose Agar medium was used to isolate the dermatophytes. The cultures were incubated at $25-300^{\circ} \mathrm{C}$ and examined weekly for 4 weeks before declaring it negative.

\section{Species identification}

The colonies if obtained were identified for the implicated fungus on the basis of gross morphology of the colonies on SDA and slide culture, microscopy and the presence of accessory structures. The microscopic examination of colonies was studied in either teased mounts or slide culture. The colonies were examined for the type of conidia, their shape, size and pattern of arrangement of hyphae/mycelial structure. The efficacy was assessed as clinical and mycological at the end of therapy and follow up period.

\section{Results}

Table1: Showing Age \& sex distribution [ $n=158]$

\begin{tabular}{|l|c|c|c|}
\hline Age group in year & Male & Female & Total $n=158(\%)$ \\
\hline$<5$ & 14 & 24 & $38(24)$ \\
\hline 6 to 10 & 42 & 70 & $112(70.8)$ \\
\hline$>10$ & 4 & 4 & $08(5)$ \\
\hline Total & $60[38 \%]$ & $98[62 \%]$ & $158[100 \%]$ \\
\hline
\end{tabular}

The age in the study population ranged from 2 to 12 years (mean 7.8 years). Majority of the patients (70.8\%) were in the age group of 6-10 years and $95 \%$ were below 10 years. Out of the 158 patients, $38 \%$ were males and $62 \%$ were females. The female to male ratio was 1.6:1 [Table 1, Fig. 1].

Table 2: Showing baseline characteristic among study participants $[\mathrm{n}=158]$

\begin{tabular}{|l|c|}
\hline Demographic profile & Total $\mathrm{n}=158(\%)$ \\
\hline Male & $60(37.6)$ \\
\hline Female & $98(62.5)$ \\
\hline Mean duration (in days) & 102.15 \\
\hline Family history & $30(20)$ \\
\hline Pets & $08(5)$ \\
\hline Overcrowding & $99(62.6)$ \\
\hline Comb sharing & $136(85)$ \\
\hline Oil application & $102(63.8)$ \\
\hline
\end{tabular}

Females were more effected $(62.5 \%)$. There was positive family history in $20 \%$ subjects. Comb sharing was one of the most important factor (85\%) followed by oil application (63.8\%) and overcrowding $(62.6 \%)$ [Table 2].

Table 3: Showing clinical symptoms in patients with T. capitis

\begin{tabular}{|l|c|}
\hline Clinical symptoms & Total (\%) \\
\hline Itching & $124(78.4)$ \\
\hline Scaling & $150(94.9)$ \\
\hline Hair loss & $110(69.6)$ \\
\hline Papules & $50(31.6)$ \\
\hline Pustules & $40(25.3)$ \\
\hline
\end{tabular}

Most common symptom in the present study was scaling, reported in $94.9 \%$ of the patients followed by itching, hair loss, and papules in $78.4 \%$, $69.6 \%$, and $31.6 \%$ of the patients respectively [Table 3].

Table 4: Showing socioeconomic status of study patients

\begin{tabular}{|l|c|}
\hline Socioeconomic status & Total, $\mathrm{n}=158(\%)$ \\
\hline Lower & $106(67)$ \\
\hline Middle & $48(30.3)$ \\
\hline Upper & $04(2.5)$ \\
\hline
\end{tabular}

Sixty seven percent patients $(106 / 158)$ in the study group belonged to lower class. Only $2.5 \%$ (4/158) patients belonged to upper class [Table 4]. Most $(60 \%)$ of the patients weight was between 20-40 $\mathrm{kg}$. Mean weight of the patients in two study groups were 20.84 and $20.58 \mathrm{~kg}$ respectively (total mean wt $20.7 \mathrm{~kg}$ ).

Table 5: Showing source of infection

\begin{tabular}{|l|c|}
\hline History of & Total $[\mathrm{n}=158(\%)]$ \\
\hline Family member infection & $30(19)$ \\
\hline Pet handling & $08(05)$ \\
\hline Farm/soil working & $120(76)$ \\
\hline
\end{tabular}

About 19\% of patients had positive family history of $\mathrm{T}$. capitis, and $5 \%$ of patients had pets in their family [Table 5].

Table 6: Showing Site of scalp involvement (localized) [ $\mathrm{n}=96$ patients]

\begin{tabular}{|l|c|}
\hline Site involved & Total $[\mathrm{n}=96(\%)]$ \\
\hline Vertex & $40(41.6)$ \\
\hline Parietal & $26(27)$ \\
\hline Temporal & $06(6.1)$ \\
\hline Occipital & $18(18.6)$ \\
\hline Frontal & $06(6.25)$ \\
\hline Total & 96 \\
\hline
\end{tabular}




\section{JMSCR Vol||07||Issue||04||Page 696-705||April}

Ninety six patients out of 158 had localized scalp involvement i.e. only one area involved out of vertex, parietal, temporal, occipital or frontal. Sixty two patients had involvement of more than one site. Out of these, 36 patients had contiguous involvement of vertex and parietal area; 4 had generalized involvement of whole of the scalp and the rest had discontinuous involvement of multiple sites. Among the patients with localized scalp involvement, vertex was the most common site involved in 40 (25\%) of the patients followed by parietal, occipital, temporal and frontal in 26 (16\%), 18(11\%), 06(3.7\%) and $06(3.7 \%)$ patients respectively [Table 6].

Table 7: Showing clinico-etiological correlation in patients with $\mathrm{T}$ capitis

\begin{tabular}{|l|c|c|c|c|c|c|}
\hline \multirow{2}{*}{$\begin{array}{l}\text { Clinical } \\
\text { variants }\end{array}$} & \multicolumn{7}{|c|}{$\begin{array}{c}\text { Etiological agent } \\
\mathrm{n}=106\end{array}$} \\
\cline { 2 - 7 } & $\begin{array}{c}\mathrm{T} . \\
\text { violeceum }\end{array}$ & $\begin{array}{c}\text { T. } \\
\text { rubrum }\end{array}$ & $\begin{array}{c}\text { T. } \\
\text { mentagrophytes }\end{array}$ & $\begin{array}{c}\text { M. } \\
\text { audouinii }\end{array}$ & $\begin{array}{c}\text { M. } \\
\text { canis }\end{array}$ & Total \\
\hline $\begin{array}{l}\text { Grey } \\
\text { patch }\end{array}$ & $30(48.3)$ & $\begin{array}{c}12 \\
(19.3)\end{array}$ & $12(19.3)$ & $2(3)$ & $\begin{array}{c}6 \\
(9.6)\end{array}$ & 62 \\
\hline $\begin{array}{l}\text { Black } \\
\text { dot }\end{array}$ & $12(75)$ & $\begin{array}{c}2 \\
(15.5)\end{array}$ & $2(12.5)$ & 0 & 0 & 16 \\
\hline Kerion & $13(48)$ & $\begin{array}{c}4 \\
(14.8)\end{array}$ & $8(29.6)$ & 0 & $\begin{array}{c}2 \\
(7.1)\end{array}$ & 27 \\
\hline Favus & $01(100)$ & 00 & 00 & 00 & 00 & 01 \\
\hline Total & $56(52.8)$ & $\begin{array}{c}18 \\
(16.9)\end{array}$ & $22(20.7)$ & $2(1.8)$ & $\begin{array}{c}8 \\
(7.5)\end{array}$ & 106 \\
\hline
\end{tabular}

Out of 62 cases of culture positive grey patch cases, T. violaceum was isolated from $48.3 \%$ cases. Other isolates recovered in grey patch variety were $\mathrm{T}$. mentagrophytes in $19.3 \%, \mathrm{~T}$ rubrum $19.3 \%, \mathrm{M}$ canis $9.6 \%$ and $\mathrm{M}$ audouinii in $3 \%$ cases. In black dot variant isolates, $75 \%$ were $\mathrm{T}$. violaceum, $12 \%$ were $\mathrm{T}$. rubrum, and $\mathrm{T}$. mentagrophyte were present in $12 \%$ of cases. In kerion $48 \%$ patients showed T.violaceum, $14.8 \%$ patients showed T. rubrum, $29.6 \%$ patients showed T. mentagrophytes, and $7 \%$ of patients showed M.canis. One patient of favus showed T. Violaceum [Table 7/Fig. 2, 3, 4].

Table 8: Showing correlation of clinical presentation with lymphadenopathy $[\mathrm{n}=90$ patients]

\begin{tabular}{|l|c|c|c|}
\hline $\begin{array}{l}\text { Clinical } \\
\text { Variant }\end{array}$ & $\begin{array}{c}\text { Cervical } \\
\text { lymphadenopathy }\end{array}$ & $\begin{array}{c}\text { Cervical and } \\
\text { Occipital } \\
\text { lymphadenopathy }\end{array}$ & Total \\
\hline $\begin{array}{l}\text { Grey patch } \\
(\mathrm{n}=88)\end{array}$ & 38 & 06 & $44(50)$ \\
\hline $\begin{array}{l}\text { Black dot } \\
(\mathrm{n}=28)\end{array}$ & 10 & 00 & $\begin{array}{c}10 \\
(35.7)\end{array}$ \\
\hline
\end{tabular}

\begin{tabular}{|l|c|c|c|}
\hline $\begin{array}{l}\text { Kerion } \\
(\mathrm{n}=41)\end{array}$ & 27 & 08 & $35(85)$ \\
\hline $\begin{array}{l}\text { Favus } \\
(\mathrm{n}=01)\end{array}$ & 01 & 00 & $\begin{array}{c}01 \\
(100)\end{array}$ \\
\hline
\end{tabular}

Lymphadenopathy was associated with the scalp lesions in 90/158 patients. Out of these 90 patients, $84 \%$ patients had cervical lymphadenopathy and $16 \%$ in addition had occipital lymphadenopathy. Majority (85\%) of the patients with kerion, had enlarged lymph nodes, followed by $50 \%$ patients of grey patch variety and $35.7 \%$ of black dot while single patients of favus reported was associated with cervical lymphadenopathy (100\%) [Table 8].

Table 9: Showing Clinical patterns in patients with T capitis

\begin{tabular}{|l|c|}
\hline Clinical pattern & Total, $\mathrm{n}=158(\%)$ \\
\hline Non Inflammatory & $116(73.4)$ \\
\hline Inflammatory & $42(26.5)$ \\
\hline
\end{tabular}

Table 10: Showing Clinical variants in patients with T capitis

\begin{tabular}{|l|c|}
\hline Clinical variants & Total, $\mathrm{n}=158(\%)$ \\
\hline Grey patch & $88(55.6)$ \\
\hline Black dot & $28(17.7)$ \\
\hline Kerion & $42(26.5)$ \\
\hline Favus & $01(0.6)$ \\
\hline
\end{tabular}

Non inflammatory variant was more common, seen in $73.4 \%$ of the patients than the inflammatory variant, seen in $26.5 \%$ of the patients [Table 9]. The most common variant of $\mathrm{T}$. capitis seen in the study population was grey patch, observed in $55.6 \%$ patients followed by kerion $26.5 \%$ and black dot in $17.7 \%$ patients respectively [Table 10/ Fig. 3, 4].

Table 11: Showing microscopic examination of hair invasion

\begin{tabular}{|l|c|c|c|c|}
\hline $\begin{array}{l}\text { Clinical } \\
\text { pattern }\end{array}$ & $\begin{array}{c}\text { Gray } \\
\text { patch }\end{array}$ & $\begin{array}{c}\text { Black } \\
\text { dot }\end{array}$ & Kerion & Total, $\mathrm{n}=158(\%)$ \\
\hline Ectothrix & 10 & 00 & 02 & $12(7.5)$ \\
\hline Endothrix & 78 & 28 & 40 & $146(92.5)$ \\
\hline
\end{tabular}

In the present study, fungal spores and hyphae were demonstrable in all the cases by direct microscopic examination with $10 \% \mathrm{KOH}$ and this was eligibility criteria for inclusion in the study. Endothrix was found in $92.5 \%$ patients while ectothrix was only present in $7.5 \%$ of patients. Ten of these patients with ectothrix had grey patch 
variant clinically and remaining 2 had kerion [Table 11/Fig. 6a, 6b].

\section{Discussion}

\section{Age Distribution}

About 158 patients were included in the study. The mean age of the study population was 7.8 years. Most of the patients were under 10 years of age only eight patients were above 10 years of age. $70.8 \%$ of total patients were between 6-10 years of age. Similar to my study, a study carried out in Sri Lanka by Kumar et $\mathrm{al}^{9}$ also reported the maximum incidence in same age group of 6-10 years. About $95 \%$ of the study population was under 10 years of age. This finding is in agreement with study by Kumar et $\mathrm{al}^{9}$ and Sahgal et $\mathrm{al}^{10}$ from Delhi, and Rohtak, who have shown a similar incidence of $79 \%$, and $88 \%$, respectively in this age group. Hussain et al ${ }^{11}$ from Pakistan reported that $95 \%$ of the study population was below 12 years of age.

\section{Sex Distribution}

In the present study, out of 158 patients, 98 $(62 \%)$ were females and $60(38 \%)$ were males with female male ratio of 1.6:1. There was an overall preponderance of girls in our study. This was also observed by Reddy et $\mathrm{al}^{12}$ and Dastghaib $\mathrm{L}$ et $\mathrm{al}^{13}$. Studies from Nepal and Brazil also showed a female preponderance with females constituting $63.6 \%$ and $64.2 \%$ of the cases of $\mathrm{T}$ capitis respectively. In contrast, Sahgal et $\mathrm{al}^{10}$ and Kumar et $\mathrm{al}^{9}$ reported equal involvement of both sexes. Equal sex distribution was also noted in studies from Pakistan and Canada.

\section{Socio-Economic Status}

About $67 \%$ of the patients in the present study belonged to lower and $30.3 \%$ to middle class. There may be a sampling bias because of the profile of patients attending government hospitals, however, our observations is in agreement with other studies from India. A Study from Pakistan by Hussain et $\mathrm{al}^{11}$ has also reported the similar findings.

\section{Weight Distribution}

Majority of the patients weighed between 20-40 $\mathrm{kg}$ in the present study. Mean weight of the patients in two groups were 20.8 and $20.5 \mathrm{~kg}$ respectively (total mean $20.7 \mathrm{~kg}$ ). Similar to our study, majority of the patients in studies by Lipozencic $\mathrm{J}$ et $\mathrm{al}^{14}$ also weighted between $20-40$ $\mathrm{kg}$. Though, the mean weight group affected in these studies is comparable to our studies, Mean weight found in these studies is in higher range of 23 to $26 \mathrm{~kg}$. The lower weight distribution in the present study can be explained on the basis of the difference in nutritional status, and built of the children in developing and developed countries.

\section{Source of Infection}

Source of infection could be traced to intra familial contact or from a sibling in $18.9 \%$ of cases in the present study. Family history was positive in $22 \%$ of the patients in study by Nawaf et $\mathrm{al}^{15}$ from Kuwait and $18 \%$ by Hussain et $\mathrm{al}^{11}$ from Pakistan. However, both Kumar et $\mathrm{al}^{11}$ and Reddy at $\mathrm{el}^{12}$ reported a little higher rate, $29 \%$ of each in their study. In the present study $5 \%$ of patients had a history of pets in their families. Sahgal et $\mathrm{al}^{10}$ and Kumar et $\mathrm{al}^{11}$ found history or rearing similar in $18 \%$ and $20 \%$ of their study population respectively. Contact with animals could act as a source of acquiring the diseases caused by zoophilic species from infected animals.

\section{Other Baseline Characteristics Comb sharing}

Sharing of combs among the family members was seen in $85 \%$ of the patients in our study. Our findings are in agreement with other studies from India. However, Singal et $\mathrm{al}^{16}$ reported sharing of combs in only $22 \%$ of the patients. Sharing of combs is an important means of transmission of infection between family members especially for anthropophilic Species.

\section{Oil Application}

Oil application was seen in $63.8 \%$ of the patients in our study which is greater as compared to other studies from South India. This can be explained 
on the basis of practice of oil application in these areas.

\section{Site of Scalp Involvement}

Approximately 96 out of 158 patients (60\%) had single area of scalp involved. in such type of scalp involvement, vertex was the most common site involved in 40 of the patients, followed by parietal, occipital, temporal and frontal in $27 \%$, $18.7 \%, 6 \%$ and $6 \%$ of patients respectively. The findings in our study are in agreement with the study carried out by Reddy et $\mathrm{al}^{12}$ where, vertex was the most common site involved followed by occipital, parietal and frontal area. However, in studies by Reddy et $\mathrm{al}^{12}$ and Kumar et $\mathrm{al}^{9}$, majority of patients had lesions at multiple sites.

\section{Clinical Symptoms}

Most common symptoms of the patients presenting with $\mathrm{T}$ capitis in our study was scaling seen in $94.9 \%$ of the patients followed by itching, hair loss, and papules in $78.4 \%, 69.6 \%$, and $31.6 \%$ of the patients respectively. Our findings are similar to the results reported by Figueroa JI et $\mathrm{al}^{17}$ in Ethopia. Bennett ML et $\mathrm{al}^{18}$ reported, itching as the predominant symptom in the majority of their patients. In contrast, hair loss (77\%) was the most common symptom reported by Singal et $\mathrm{al}^{16}$ and Reddy et $\mathrm{al}^{12}$.

\section{Lymphadenopathy}

This parameter has not been compared with the clinical presentation in any of the earlier studies $\mathrm{T}$. capitis. In the present study, $85 \%$ of the patients with kerion and $100 \%$ case of favus had enlarged lymph nodes. The higher incidence of lymphadenopathy associated with inflammatory variants may be considered as a part of the host immune response to greater inflammatory disease processes.

\section{Clinical Variants}

Non inflammatory variants $(73 \%)$ were more common than the inflammatory variants. This is in accordance with majority of the previous studies from India and west. Singal et $\mathrm{al}^{16}$ reported a much higher incidence of $84 \%$ of non inflammatory variants in their study. The most common variant of $T$ capitis seen in the study population was grey patch $(55.6 \%)$ followed by kerion, black dot variety and favus. Grey patch has been commonest variant seen in majority of the studies from India. Reddy et $\mathrm{al}^{12}$ and Verma et $\mathrm{al}^{19}$ observed this variant in $44 \%$ and $50 \%$ of their study population, while most of the other studies have reported a relatively lower incidence of 30$40 \%$. Black dot variant was present in $17.7 \%$ patients in our study. Our findings are in agreement with that of Kumar et $\mathrm{al}^{9}$. Other studies from Delhi reported a lower incidence of $8 \%$ while studies from Lahore and Kuwait have reported a higher incidence of $30 \%$.

Kerion was observed in $26 \%$ of all our cases. The incidence of kerion has greatly varied in other studies. Sehgal et $\mathrm{al}^{10}$ reported kerion in $18 \%$, while Kumar et $\mathrm{al}^{9}$ and Singal et $\mathrm{al}^{16}$ observed an incidence of $10 \%$ and $6.5 \%$ respectively in their studies. The studies from South India and Pakistan have reported a higher incidence of up to $30 \%$. Favus was reported in $0.6 \%$ of cases. It is in accordance with rare incidence of favus in other studies from india.

\section{Microscopic Examination}

In our study, majority of dermatophytes were endothrix $(92.5 \%)$. This finding is in agreement with Sehgal et $\mathrm{al}^{10}$ and Kumar et $\mathrm{al}^{9}$. However, Singal et $\mathrm{al}^{16}$, Gururaj et $\mathrm{al}^{20}$ and Reddy et $\mathrm{al}^{12}$ reported a relatively lower incidence ranging between $50-60 \%$.

\section{Fungal Culture}

In the present study, fungal culture was positive in $66.6 \%$ of the total cases. This is in concordance with results by Singal et al. ${ }^{16}$ Contrary to this, Sehgal et $\mathrm{al}^{10}$ and Dastghaib L et $\mathrm{al}^{13}$ showed a higher rate of isolation of $74 \%$ and $84 \%$ respectively while a lower isolation rate of $47 \%$ was reported by Kumar et al. ${ }^{9}$ Studies from Turkey and Kenya have also shown higher isolation rates of $83 \%$ and $73 \%$ respectively. Higher isolation rates in the west may be because of the better isolation techniques in the developed countries. 


\section{Etiological Agents}

In the present study, $T$. violaceum was the commonest isolate followed by T. mentagrophyte, $\mathrm{T}$ rubrum and $\mathrm{M}$ canis. $\mathrm{M}$ audouinii was the least common isolate. T. violaceum has been reported as the predominant isolate by most of previous authors such as Sehgal et $\mathrm{al}^{10}$ and Reddy et $\mathrm{al}^{12}$ $(67 \%)$, Kumar et $\mathrm{al}^{9}(40 \%)$ and Singal et $\mathrm{al}^{16}$ $(38 \%)$. Our findings are also in agreement with various overseas studies from Pakistan, Libya, Nepal and Iran. T. mentagrophytes was the second most common isolate in our study, seen in $21 \%$ of the patients. This isolation rate is higher as compared to previous studies from India, which have reported it in only $3 \%$ of the total cases. Studies from Nepal and Italy have shown a similar incidence to our study.

M. Canis and M. audouinii were uncommon isolates in our studies reported in only $7.54 \%$ and $1.88 \%$ of patient respectively. Kumar et $\mathrm{al}^{9}$ and Sehgal et $\mathrm{al}^{10}$ has not reported any case due to Microsporum species in their studies. In contrast M. audouinii and M. canis were reported in $13.15 \%$ and $10 \%$ of the cases respectively by Gururaj et $\mathrm{al}^{20}$. M. canis was the predominant organism found in studies carried out in Spain $(62 \%)$ and Italy (82\%) in 1997. Higher isolation rates of M. canis from west reflects the practice of keeping pets at homes.

\section{Clinico-etiological Correlation}

Grey patch: T. violeceum was the most common isolate recovered in $48.3 \%$ of the cases of grey patch followed by T. mentagrophytes, T. rubrum, M. canis and M. audouinii. T violeceum has been the major isolate in grey patch variety in other studies from India and neighbouring countries. In Italy Singhal et $\mathrm{al}^{16}$ noted M. audouinii as the most common isolate in grey patch variety in their study.

T. mentagrophytes were the second most common $(19.3 \%)$ isolates from the grey patch variety in our study [Fig. 7]. Gujraj et $\mathrm{al}^{20}$ reported $17.5 \%$ of this agent in their study. T. rubrum was isolated in $19.3 \%$ of the total isolates of grey patch variety in our study. This data is in agreement with Singhal et $\mathrm{al}^{16}$ and Kumar et $\mathrm{al}^{9}$ who reported T. rubrum as second most common isolates in their study. $\mathrm{M}$. canis was isolated in $9.6 \%$ of total isolates of grey patch variety in our study. Studies from Tirupathi and Puddichery have reported M. canis in $6 \%$ and $4 \%$ of cases of their total grey patch isolates respectively.

Black dot: $T$. violaceum was the predominant pathogen $(75 \%)$ in black dot variant. This is in agreement with most of the studies from India. Studies from Pakistan and Kuwait have also confirmed the similar findings. In contrast, $\mathrm{T}$. tonsurans was the most common isolate recovered from patients of black dot variant by Singal et al ${ }^{16}$. In the present study, all patients with this variant showed, endothrix, on microscopic examination, correlating well with the clinical presentation.

Kerion: Kerion is caused by both anthropophilic and zoophilic species. Thus, the isolates in this variant has also varied considerably in different studies. In the present study, $\mathrm{T}$ violaceum was commonest isolate in kerion followed by $\mathrm{T}$ mentagrophytes and $\mathrm{T}$ rubbrum. Similar to our study, $\mathrm{T}$ violeceum was the predominant pathogen isolated in kerion by Dastghaib $\mathrm{L}$ et al. ${ }^{13}$ However, the most common species recovered in previous studies from Delhi were $T$ mentagrophytes, $\mathrm{T}$ verrucosum and $\mathrm{M}$ audouinii respectively. Other species like $\mathrm{T}$ rubrum and $\mathrm{T}$ tonsurans and have also been isolated.

Favus: In our study only one case of favus was recorded. It is in accordance with rare incidence of favus, from various studies from India [Fig. 5].

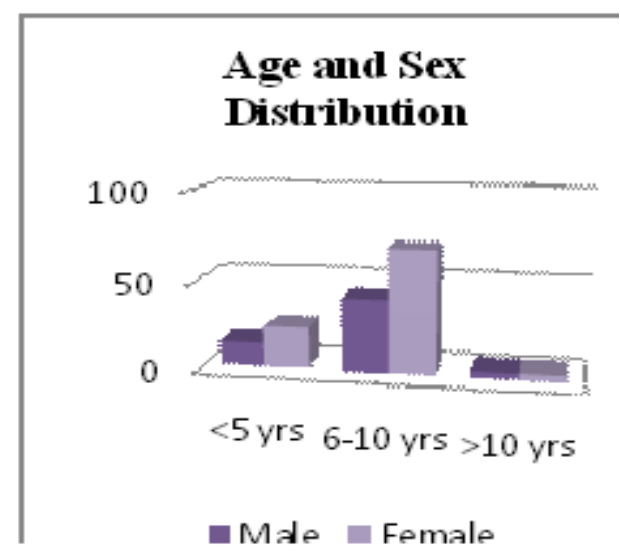

Figure 1: Distribution of study subjects 


\section{JMSCR Vol||07||Issue||04||Page 696-705||April}

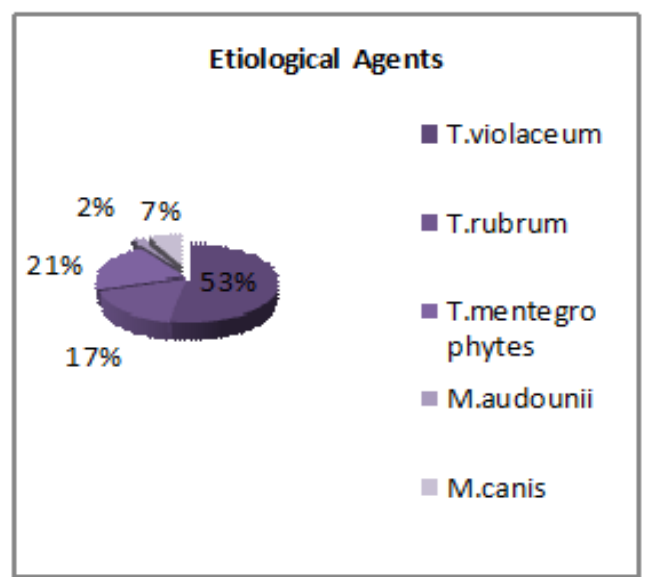

Figure 2: Types of tinea infection among study participants

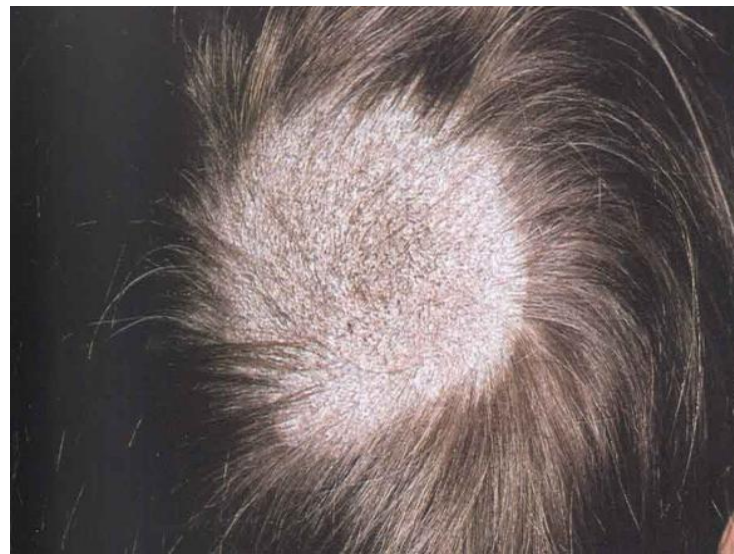

Figure 3: Grey patch of T. capitis

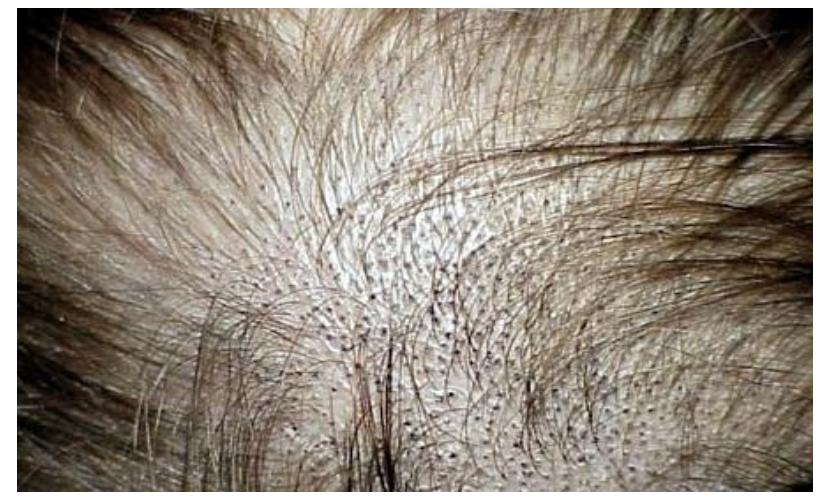

Figure 4: Black Dot T. Capitis

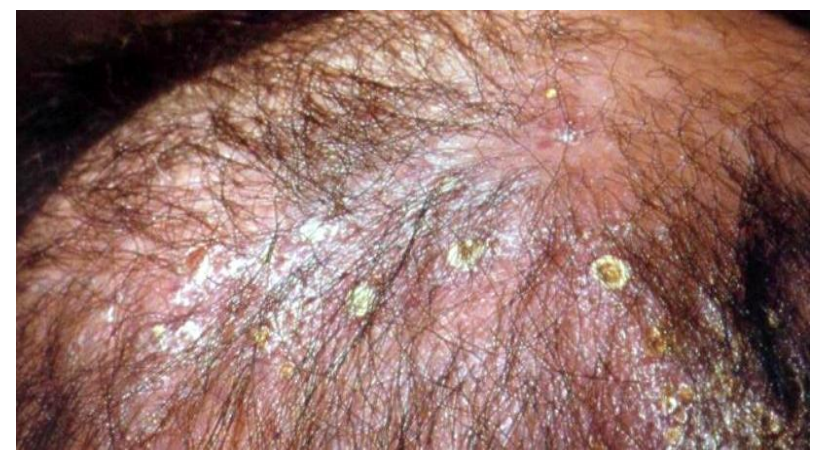

Figure 5: Favus T. capitis

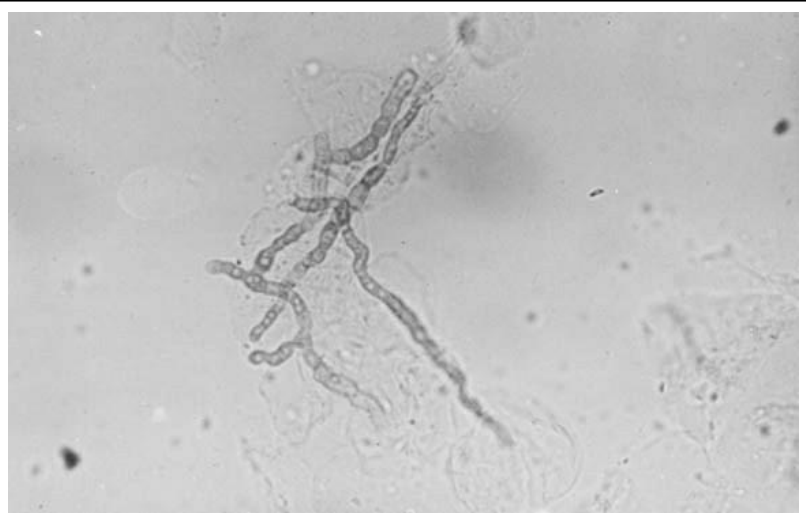

Figure 6a: $\mathrm{KOH}$ microscopic appearance of hyphae and spores

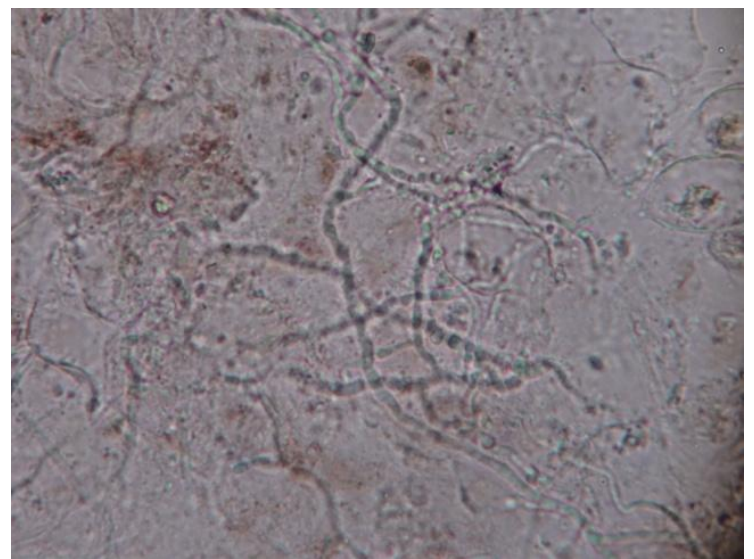

Figure 6b: $\mathrm{KOH}$ microscopic appearance of hyphae and spores
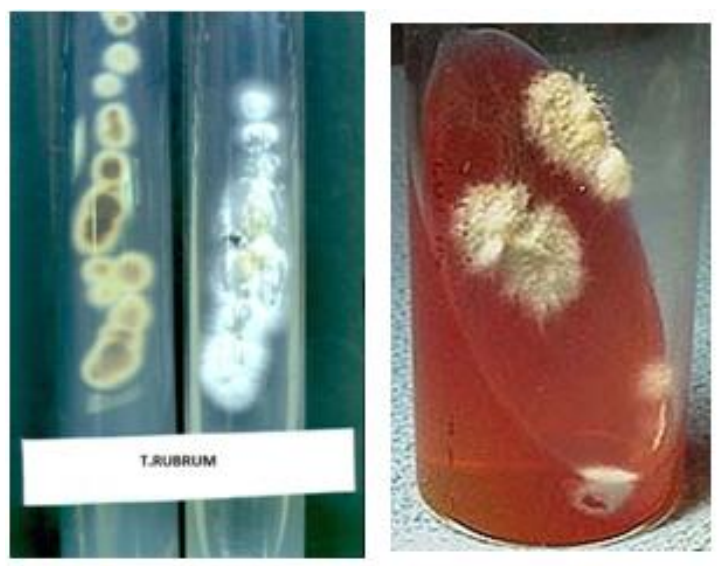

Figure 7: T. Mentagrophytes

\section{Conclusion}

About $92.5 \%$ of the study population revealed endothrix on $\mathrm{KOH}$ microscopic examination and $7.5 \%$ had ectothrix. T. violeceum was found in $52.8 \%$ of the cases of grey patch, followed by $\mathrm{T}$. rubrum, $\mathrm{T}$.mentagrophyte, $\mathrm{M}$ canis and $\mathrm{M}$ audouinii found in $16.9 \%, 20.7 \%, 7.54 \%$ and 1.88 $\%$ patients respectively. $\mathrm{T}$. violeceum was the 
predominant pathogen found in $75 \%$ of black dot variety. The isolate seen in seborrheic variant was T. Mentagrophytes. T. violeceum was isolated in $50 \%$ of kerion followed by T. mentagrophytes and T. rubrum in $28 \%$ and $7 \%$ respectively.

Grey patch is the most common variant of $\mathrm{T}$ capitis. T. violaceum is the most common isolate in all the clinical variants of $\mathrm{T}$ capitis in North eastern part of India. Anthropophilic species are responsible mainly for non inflammatory variants and zoophilic species for inflammatory variants. Intra-familial and animal contacts are major source of the source of infection.

\section{References}

1. Bhat YJ, Zeerak S, Kanth F, Yaseen A, Hassan I, Hakak R. Clinicoepidemiological and mycological study of tinea capitis in the pediatric population of Kashmir valley: A study from a tertiary care centre. Indian Dermatol Online J 2017; 8:100-3.

2. Gupta AK, Summerbell RC. Tinea Capitis. Med Mycol 2000; 38:255-87.

3. Havlickova B, Czaika VA, Friedrich M. Epidemiological trends in skin mycoses worldwide. Mycoses 2008; 4:2-15.

4. Kundu D, Mandal L, Sen G. Prevalence of Tinea capitis in school going children in Kolkata, West Bengal. J Nat Sci Biol Med. 2012; 3(2):152-5.

5. Pai VV, Hanumanthayya K, Tophakhane RS, Nandihal NW, Kikkeri NN. Clinical study of Tinea capitis in Northern Karnataka: A three-year experience at a single institute. Indian Dermatol Online J 2013; 4:22-6.

6. Menan El, Zongo Bonou O, Rouet F, Kikibarro PC. Tinea capitis in school children from Ivory coast (western Africa) A 19981999 cross sectional study. Int J Dermatol. 2002; 41:204-7.

7. Ginter-Hanselmayer G, Weger W, Ilkit M, Smolle J. Epidemiology of tinea capitis in Europe: current state and changing patterns. Mycoses. 2007;50 Suppl 2:6-13.

8. Sahai S, Mishra D. Change in spectrum of dermatophytes isolated from superficial mycoses cases: First report from Central India. Indian J Dermatol Venereol Leprol 2011;77:335-6.

9. Kumar V, Sharma RC, Chander R, Clinicomycological study of tinea capitis. Ind J dermatol Venerol 1965; 31:1-5.

10. Sahgal VN, Saxena AK, Kumari S. Tinea capitis. A clinicoetiologic correlation. Int J Dermatol 1985; 24(2): 116-119.

11. Hussain I, Muzaffar F, Rashid T, et al. A randomized, comparative trial of treatment of kerion celsi with griseofulvin plus oral prednisolone vs. griseofulvin alone. Med Mycol 1999; 37:97-99.

12. Reddy et al. Clinico-mycological study of tinea capitis in Pondicherry. Ind. J dermatol Venerol 1991; 57: 180-182.

13. Dastghaib L, Azizzadeh M, Jafari P. Therapeutic options for the treatment of tinea capitis: Griseofulvin versus fluconazole. J Dermatol Treat 2005; 16:43-6.

14. Lipozencic J, Skerlev M, Orofino-Costa R, et al. A randomized, double-blind, parallelgroup, duration-finding study of oral terbinafine and open-label, high-dose griseofulvin in children with tinea capitis due to Microsporum species. $\mathrm{Br} \mathrm{J}$ Dermatol. 2002; 146:816-823.

15. Nawaf AM, Joshi A, Zaki A, Nour-Eldin O, Al-Sheltawy M, El-Adawy I, Sharma AK.

Tinea capitis among children and adolesce nts in the Farwaniya region of Kuwait. $\mathbf{J}$ Dermatol. 2003 Dec;30(12):904-9.

16. Singal A, Rawat S, Bhattacharya SN, Mohanty S, Baruah MC, Clinicomycological profile of tinea captis in North India and response to griseofulvin. $\mathbf{J}$ dermatol 2001; 28(1): 22-26.

17. Figueroa JI, Hawranek T, Abraha A, Hay RJ. Tinea capitis in south-western 
Ethiopia: a study of risk factors for infection and carriage. Int $\mathrm{J}$ Dermatol 1997; 36:661-666.

18. Bennett ML, Fleisher AB, Loveless JW, Feldman SR. Oral griseofulvin remains the treatment of choice for tinea capitis in children. Pediatr Dermatol 2000; 17:304-9.

19. Verma S, Madhu R. The Great Indian Epidemic of Superficial Dermatophytosis: An Appraisal. Indian J Dermatol. 2017;62(3):227-236.

20. Gururaj K, Lakshmi N. Tinea capitis in Tirupati, Ind. J. Pathol Microbial 1990; 33: 360-363. 